\title{
ДИНАМИКА СОВЕТСКО-ЮГОСЛАВСКИХ ТОРГОВЫХ ОТНОШЕНИЙ КАК ФАКТОР ФОРМИРОВАНИЯ ВНЕШНЕПОЛИТИЧЕСКОЙ СТРАТЕГИИ ФНРЮ В 1948-1955 ГГ.
}

В статье представлен анализ динамики торговых связей между Югославией и СССР, начиная с возникновения советско-югославского конфликта 1948 г. и заканчивая нормализацией отношений между странами, и, как результат - подписанием торговых соглашений в 1955 г. Через рассмотрение торгового оборота, его количественного и качественного состава выявляются особенности торговых контактов между двумя странами. Автор отмечает уменьшение торгового оборота между ФНРЮ и СССР в 1948 г. вследствие советско-югославского конфликта, а затем и полное его прекращение, в связи с чем югославскому руководству пришлось налаживать торговые взаимоотношения с капиталистическими странами.

В статье отмечается, что после смерти И. В. Сталина начался процесс постепенной нормализации связей между ФНРЮ и СССР, и в 1953 г. были восстановлены дипломатические контакты. Однако возобновление экономических отношений произошло лишь в 1955 г., когда в Москве были подписаны торговые соглашения о взаимных поставках товаров на 1955 г. в размере 40 млн руб. с каждой стороны. Автор подчеркивает, что перечень югославской продукции и сырья, предназначавшихся для поставок в СССР, ограничивался второ- степенно продукцией, в то время как советский список включал стратегические товары. Причиной такого дисбаланса стали обязательства ФНРЮ перед США о поставке им стратегического сырья, что сделало невозможным его поставки в СССР.

Автор отмечает, что, несмотря на отказ от взаимных экономических претензий и восстановление торговых связей с СССР и странами социалистического лагеря, отказа от торговли с капиталистическими странами не последовало. Это явилось одной из причин того, что сотрудничество югославского и советского руководства по партийной линии не было столь же успешным. Автор приходит к выводу, что на фоне складывающейся системы экономических связей происходила выработка югославской стороной собственного курса взаимоотношений со странами коммунистической и социалистической ориентации.

Актуальность данной статьи обусловлена недостаточной изученностью вопросов, связанных с экономическими, в том числе торговыми связями Югославии и CCCP.

Ключевые слова: Югославия, ФНРЮ, СССР, советско-югославский конфликт 1948 г., советско-югославские торговые отношения.
The article analyzes the dynamics of trade relations between Yugoslavia and the USSR starting the emergence of the Soviet-Yugoslav conflict of 1948 and up to normalization of relations between the countries that resulted in signing trade agreements in 1955. The peculiarities of trade contacts between the two countries are revealed through the consideration of trade turnover, its quantitative and qualitative composition. There was a decrease in trade turnover between the FPRY and the USSR in 1948 due to the Soviet-Yugoslav conflict, later followed by its complete cessation. In this regard, the Yugoslav leadership had to establish trade relations with the capitalist countries.

The article notes that the process of gradual normalization of ties between the FPRY and the USSR began after the death of I.V. Stalin, and in 1953 the diplomatic contacts were resumed. However, the resumption of economic relations occurred only in 1955, when both sides signed the trade agreements on mutual deliveries of goods for 1955 at a total cost of 40 million rubles in Moscow. The author emphasizes that the list of Yugoslavian products and raw materials intended for delivery to the USSR was limited to minor products, while the Soviet list included strategic goods. The reason for the disbalance was the commitment of FPRY to the USA to supply strategic raw materials, which made its delivery to the USSR impossible.

The author underlines that despite the rejection of mutual economic claims and the resumption of trade relations with the USSR and the countries of the Soviet bloc, there was no renunciation of trade with the capitalist countries. The author concludes that the Yugoslav side developed its own course of relations with the countries of communist and socialist orientation against the backdrop of the emerging system of economic ties.

The relevance of the article is due to insufficient knowledge of issues related to economic, as well as trade relations between Yugoslavia and the USSR.

Key words: Yugoslavia, FPRY, the USSR, Soviet-Yugoslav conflict of 1948 , Soviet-Yugoslav trade relations. 
Советско-югославский конфликт 1948 г. стал ключевым моментом в отношениях между Югославией и СССР, оказавшем влияние не только на политические, но и на экономические, в том числе торговые связи двух стран. Изучение качественных и количественных характеристик торгового оборота между ФНРЮ и СССР позволяет понять динамику взаимоотношений двух стран, а также механизмы их нормализации, задействованные в процессе восстановления международных контактов, их влияния на формирование внешнеполитической стратегии Югославии в целом. В настоящее время обращение к данной теме обусловлено желанием РФ выстраивать взаимовыгодные отношения со странами Балканского региона с учетом имеющегося исторического опыта

В отечественной литературе к данной проблематике обращались такие известные исследователи, как В. С. Милованов [7], А. А. Костин [3, 4] М. А. Максакова [6], А. Б. Едемский [2], А. С. Стыкалин [21], а из зарубежных ученых - Л. Матес [22], И. Лакович [5]. Однако первостепенное внимание в работах уделялось политическим, партийным связям Югославии и СССР, а вопросы экономического, в частности, торгового сотрудничества, на наш взгляд, изучены недостаточно.

Рассмотрение особенностей советско-югославских торговых отношений целесообразно начать с событий лета 1948 г., когда под влиянием политических событий разрушалась прежняя система международных отношений.

После опубликования резолюции Информационного бюро коммунистических и рабочих партий «О положении в Коммунистической партии Югославии» от 29 июня 1948 г. [14], ознаменовавшей начало советско-югославского конфликта, в правящих кругах ФНРЮ начинают говорить о невыполнении Советским Союзом экономических обязательств по отношению к Югославии. По мнению югославской стороны, это приносило «большие трудности в течение 1948 года» [18, л. 11; 16, л. 97]

В связи с этим высказывалось мнение о том, что необходимо расширить торговые взаимоотношения с капиталистическими странами. Так, секретарь Загребского городского комитета компартии Шпильян в сентябре 1948 г. высказал мнение о том, что если СССР и страны народной демократии осуществят экономическую блокаду Югославии, то она будет торговать с капиталистическими странами. По его мнению, такая торговля будет оправдана, потому что «СССР вел торговлю с Югославией как с обычной капиталистической страной, продавая ей товары плохого качества» $[15$, л. 130-131]. Отмечалось, что Югославия не должна быть источником сырья для стран, у которых развита мощная промышленность (под которыми, по нашему мнению, в первую очередь подразумевался СССР), и покупать у них продукцию по дорогой цене [18, л. 4]. Следует отметить, что в середине 1950-х гг, когда ФНРЮ уже имела высокий товарооборот с США, главной статьей ее экспорта были цветные металлы. Югославия осталась источником сырья для страны с мощной экономикой, однако на этот раз для США.
Ухудшение политических взаимоотношений между Югославией и СССР привело к ослаблению экономических связей. В период с 1945 по 1947 гг. на долю СССР приходилось свыше 1/5 общего югославского товарооборота с другими странами [7, с. 41]. В 1947 г. удельный вес СССР в югославском экспорте составил $16,58 \%$, а в импорте - 45,79\% [4, с. 98]. Общий товарооборот стран в 1947 г. составил 60,5 млн руб., а в 1948 г. 72,7 млн руб. В 1949 г. произошло резкое сокращение торгового оборота, который по сравнению с предыдущим годом уменьшился почти в 6 раз и составил 12,2 млн руб. [1, с. 66].

В иностранной прессе, в частности в итальянских газетах, с конца 1948 г. стали появляться сообщения о взаимоотношениях Югославии с западными странами, в том числе о секретном соглашении между ФНРЮ и США в экономической, политической и военной областях. Югославская пресса объясняла это интригами американских империалистов, «которые пытаются добиться для себя выгоды: изолировать нашу страну и обострить разногласия по некоторым вопросам между Югославией с одной стороны, Советским Союзом с другой стороны» [15, л. 246-249]. Также подчеркивалось, что США и Югославия не имеют никаких торговых договоров, хотя идут переговоры о заключении договора с англо-американской зоной оккупации в Германии. С советской зоной договор был подписан [18, л. 31]. Таким образом, несмотря на возникшие между ФНРЮ и СССР разногласия, а также на заявления отдельных партийных функционеров о возможности торговли с капиталистическими странами, любые сообщения о существовании таковых опровергались официальной югославской прессой.

Несмотря на данную позицию югославской стороны, проблема смены внешнеэкономического партнера требовала решения, особенно в связи с денонсацией 28 сентября 1949 г. Договора о дружбе, взаимной помощи и послевоенном сотрудничестве между ФНРЮ и СССР и разрывом дипломатических отношений. 19 ноября 1949 г Коминформом была принята новая резолюция «Коммунистическая партия Югославии во власти шпионов и убийц", а затем в 1950 г. последовало полное прекращение экономических связей с СССР и странами народной демократии.

В декабре 1950 г. член ЦК КПЮ Б. Кидрич на заседании Скупщины заявил, что разрывом инвестиционных договоров СССР и страны народной демократии нанесли ФНРЮ ущерб в 400 млн долл. [3, с. 59]. Данные события сопровождались ухудшением экономической ситуации внутри Югославии: невыполнением и продлением пятилетнего плана (1947-1952 гг.), следствием которого были народные займы 1948 и 1950 гг., а также засухой 1950 г. [2, с. 596] К тому же, после разрыва отношений СССР потребовал от Югославии оплатить долг в размере 276,2 млн руб. $[17$, л. 35-38].

Указанные события привели к тому, что руководство ФНРЮ начало переговорный процесс по сотрудничеству с капиталистическими странами, 
в том числе США. Сведения о торговле Югославии со странами Запада использовались представителями официальных кругов Советского Союза для пропаганды против режима И. Б. Тито. Обзоры прессы о растущем экспорте стратегического сырья, такого как медь, свинец и другие цветные металлы в Соединенные Штаты Америки [16, л. 28,170$]$ заканчивались, как правило, выводами о том, что все это является «доказательством того, что преступная клика Белграда добровольно предоставляет свою помощь для подготовки антисоветской войны» $[16$, л. 714].

В период с 1950 по 1953 гг. торговый оборот между ФНРЮ и СССР практически отсутствовал (в статистических сборниках в графрах «экспорт» и «импорт» указывается значение «0», где «0»это значение, которое составляет меньше половины значения за прошлый год. Последние имеющиеся данные относились к 1949 г., в котором значения импорта и экспорта Югославии составляли соответственно 2,6 и 9,6 млн руб.) [1, с. 66; 23, s. 212 ]

Смерть И. В. Сталина в 1953 г. и постепенный пересмотр советским руководством отношения к режиму И. Б. Тито стали толчком к нормализации экономических отношений ФНРЮ с СССР. Летом 1953 г. были восстановлены дипломатические связи $[10$, с. $574 ; 11$, с. 575$]$.

Вопрос возобновления экономических контактов между странами подробно обсуждался в ЦК КПСС. Послу СССР в Югославии В. А. Валькову были даны указания самому не проявлять инициативы в деле восстановления экономических отношений. Тем не менее, в случае проявления инициативы с югославской стороны, советский посол должен был «дать понять югославам», что возобновление торговли возможно, но после урегулирования вопроса о погашении задолженности Югославии СССР [8, с. 577].

Стоит отметить, что инициатором восстановления торговых отношений действительно стала югославская сторона, которая «предложила вначале заключить компенсационное соглашение, а затем вести переговоры о торговом соглашении» [6, с. 20]. Компенсационное соглашение было подписано в Белграде 1 октября 1954 г. Согласно документу были предусмотрены поставки товаров до 1 апреля 1955 г. на сумму 10 млн руб. с каждой стороны [6, с. 20].

18 декабря 1954 г. в Москву прибыла правительственная торговая делегация ФНРЮ во главе с членом Исполнительного Вече Югославии М. Тодоровичем [13]. В результате состоявшихся переговоров 5 января 1955 г. были подписаны торговое и платежное соглашения. Стороны обязались обеспечить взаимные поставки товаров на 1955 г. в размере 40 млн руб. с каждой стороны $[20$, л. 1-10].

Из письма ЦК КПСС центральным комитетам коммунистических и рабочих партий Китая, Польши, Чехославакии, Румынии, Венгрии, Болгарии, Германии, Алюании, Кореи, Франции и Италии (ему предшествовала переписка ЦКК КПСС и ЦЦК
СКЮ) известны подробности экономических переговоров между Югославией и СССР Члены СКЮ, высказывавшись за улучшение отношений с Coветским Союзом и странами народной демократии, хотели в то же время «сохранить свои тесные экономические и политические связи с капиталистических странами», и были намерены «неуклонно выполнять свои, по их выражению, «огромные обязательства» перед Западом» [12, с. 609].

В данном документе при упоминании переговоров подчеркивалось, что члены югославской делегации ограничивали список товаров лишь “второстепенными материалами» [12, с. 609]. И действительно, в списке для поставки из ФНРЮ в СССР значились: мясо и мясные консервы, табак и сигаретная бумага, пенька, карбид кальция, сода каустическая, сода кальцинированная, спирт этиловый, верхняя кожа, фанера ножевая, шерстяные ткани, бараньи кишки. Машины и изделия из металла должны были быть поставлены на сумму 500 тыс. долл. (для сравнения шерстяных тканей должно было быть поставлено на 1 млн долл.) [20, л. 5]. В список поставок товаров из СССР в Югославию значились: нефть, авиабензин и другие нефтепродукты, антрацит, марганцевая руда, асбест, магнезия, химические и фармацевтические товары, хлопок, газетная бумага, а также машины и изделия из металла на сумму 500 тыс. долл. [20, л. 6].

На предложения советской стороны включить в список поставляемых в СССР товаров «медь, (морские) суда и т. п.», югославы ответили, что эти и другие стратегические товары ФНРЮ не может поставлять СССР в силу своих «моральных обязательств» перед США» [12, с. 609].

По мнению ЦК КПСС данная позиция свидетельствовала о том, «Что руководство югославской партии серьезно завязли в своих экономических и политических связях с капиталистических миром" и подобная позиция югославской стороны наглядно демонстрировала, что «политика югославский руководителей в ряде важных вопросов (пока что) в настоящее время идет в фарватере империалистической политики США» [12, с. 609].

Несмотря на вышеуказанные противоречия Президиум ЦК КПСС 1 июля 1955 г. вынес постановление «считать целесообразным отказаться от старых взаимных экономических претензий» $[9$, с. 627]. В свою очередь, Югославия отказалась от претензий к СССР, «связанных с материальными издержками конфликта между Сталиным и Тито» $[21$, с. 205].

Таким образом, постепенно Советский Союз вновь стал важным стратегическим партнером во внешней торговле ФНРЮ. В 1954 г. вырос товарооборот с СССР, в котором, по мнению югославской стороны, наблюдалось «ненужное превышение» экспорта над импортом [19, л. 169]. Если в 1953 г. СССР вообще не был представлен в товарообороте Югославии, а в 1954 г. удельный вес СССР как в экспорте, так и в импорте ФНРЮ не достигал и $1 \%$, то в 1955 г. в импорте Югославии он занимал $3,3 \%$, а в экспорте $-7 \%$ [24, s. 200] Таким образом, СССР занимал 7 место в импорте 
Югославии и 5 в экспорте. Одновременно, с 1954 г начал развиваться товарообмен со странами Восточной Европы [19, л. 169].

Несмотря на восстановление экономического сотрудничества между ФНРЮ и СССР, сотрудничество двух стран по партийной линии вследствие идеологических разногласий не было столь успешным. Об этом говорит и вывод, который делают члены ЦК КПСС в вышеуказанном письме центральным комитетам коммунистических и рабочих партий: «... стремление югославских руководителей сидеть на двух стульях, занимать якобы независимую позицию между двумя лагерями находит объяснение не только в возросшей за последнее время экономической зависимости Югославии от США и Англии, но и в отходе руководителей СКЮ от марксизма-ленинизма ... Мь не должны особенно рассчитывать на возможность сотрудничества с югославами по партийной линии, так как такое сотрудничество возможно лишь на идейной основе признания принципов марксизма-ленинизма». В том же документе отмечалось намерение СССР «добиваться отрыва Югославии от империалистического лагеря или по крайней мере, ослабления связей Югославии с этим лагерем» и расширение «возможности коммунистического влияния на народы Югославии» $[12$, с. 611$]$

В своей деятельности в области внешней торговли Югославия стояла на той точке зрения, "что успешное разрешение экономических проблем и развитие взаимного сотрудничества» будут способствовать устранению причин будущих конфликтов и упрочнению международного положения и мира во всем мире» $[19$, л. 175176]. И действительно, активное экономическое сотрудничество между ФНРЮ и СССР помогли не допустить повторения советско-югославского конфликта 1948 г., несмотря на наличие разногласий, в том числе по идеологическим вопросам.

Таким образом, динамика экономических, и в частности, торговых взаимоотношений Югославии и СССР явилась основополагающим фактором для формирования внешнеполитической стратегии югославской политической элитой в 1948-1954 гг. Прекращение советской экономической и военной помощи, разрыв торговых связей между ФНРЮ и странами социалистического лагеря привел к тому, что югославское руководство было вынуждено налаживать связи с капиталистическими странами, в том числе и США.

Взаимоотношения Югославии с СССР в середине 1950-х гг. можно сравнить со взаимоотношениями ФНРЮ и США в период советско-югославского конфрликта 1948-1953 гг. США в 1948-1949 гг оказывали экономическую поддержку Югославии, добиваясь ее окончательного отрыва от СССР и стран народной демократии. Советский Союз в 1954 г. стремился вернуть ФНРЮ в социалистический лагерь, используя экономические и культурные связи. И в том, и в другом случае наблюдалось отсутствие идеологического единства, что приводило к трудностям в сотрудничестве по партийной линии (в случае с СССР) и в политической сфере (в случае с США). В вопросах военного сотрудничества Югославия также не стремилась брать на себя обязательств. ФНРЮ так и не стала полноценным членом ОВД, последовательно дистанцировалась от блока НАТО и отказалась от военной помощи США [5, с. 214], явившись одной из стран-основателей Движения Неприсоединения.

Несмотря на улучшение взаимоотношений с СССР, прекращения экономических связей Югославии с США не последовало. Тем не менее, «западным кругам с надеждой на установление господства над Югославией пришлось расстаться» [22, s. 127]. Однако и в отношениях с СССР не произошло ожидаемого советским партийным руководством тесного сближения с СКЮ. Югославия не взяла на себя никаких обязательств в отношении социалистического лагеря и идеологического единства. Испытывая давление как со стороны США, так и со стороны СССР, И. Б. Тито, не отказываясь от экономического сотрудничества ни с той, ни с другой сторонами, повел курс на построение собственной экономической модели социализма и равноудаленность от двух блоков.

\section{Источники и литература}

1. Внешняя торговля СССР. Статистический сборник. 1918-1966. М.: Международные отношения, 1967. 245 с.

2. Едемский А. Б. Югославия в 50-е годы: в поисках «аутентичного» марксизма» // Югославия в XX веке: Очерки политической истории. Отв. ред. К. В. Никифоров. М.: Индрик, 2011. С. 595-616.

3. Костин А. А. «Прощай, дядя Джо! Здравствуй, дядя Сэм!»: роль США в развитии отношений Югославии с Западом в 1949-1953 гг. // Вестник Вятского государственного университета. 2011. №4-1 История. Исторические науки. C. $57-68$.

4. Костин А. А. Экономические отношения Югославии и Соединенных Штатов 1945-1948 гг. // Ярославский педагогический вестник. 2011. №3. Т.I (Гуманитарные науки). С. 96-101.

5. Лакович И. Переориентация югославской военной политики (1956-1961 гг.). // Славянский мир в третьем тысячелетии. Соглашение (согласие), договор, компромисс в истории, языках и культуре славянских народов. М.: Ин-т славяноведения РАН, 2016. С. 209-224.

6. Максакова М. А. Тенденции развития экономического сотрудничества России и стран Западных Балкан: автореф. дисс.. канд. эконом. наук. М., 2015. 20 с.

7. Милованов В.С. Советско-югославские экономические отношения. М.: Наука, 1978. 152 с

8. Постановление Президиума ЦК КПСС «О возобновлении экономических и культурных связей между СССР и Югославией» // Встречи и переговоры на высшем уровне руководителей СССР и Югославии в 1946-1980 гг: В 2 т. Т. 1 1946-1964 / гл. ред. М. Милошевич, В. П. Тарасов, Н. Г. Томилина. М.: МФД, 2014. 880 с. (Россия. ХХ век. Документы) C. $575-578$. 
9. Постановление Президиума ЦК КПСС «О мероприятиях по развитию советско-югославских отношений» // Встречи и переговоры на высшем уровне руководителей СССР и Югославии в 1946-1980 гг: В 2 т. Т. 1: 1946-1964/ гл. ред. М. Милошевич, В. П. Тарасов, Н. Г. Томилина. М.: МФД, 2014. 880 с. (Россия. ХХ век. Документы). С. 627.

10. Постановление Президиума ЦК КПСС «Об агремане послу Югославии в СССР Видич Добривое» // Встречи и переговоры на высшем уровне руководителей СССР и Югославии в 1946-1980 гг: В 2 т. Т. 1: 1946-1964 / гл. ред. М. Милошевич, В. П. Тарасов, Н. Г. Томилина. М.: МФД, 2014. 880 с. (Россия. ХХ век. Документы). С. 574-575.

11. Постановление Президиума ЦК КПСС «Об указаниях совпослу в Югославии» // Встречи и переговоры на высшем уровне руководителей СССР и Югославии в 1946-1980 гг: В 2 т. Т. 1: 1946-1964 / гл. ред. М. Милошевич В. П. Тарасов, Н. Г. Томилина. М.: МФД, 2014. 880 с. (Россия. ХХ век. Документы). С. 575.

12. Постановление Президиума ЦК КПСС «Проект резолюции Президиума ЦК КПСС по докладу правительственной делегации СССР о переговорах с Югославией» // Встречи и переговоры на высшем уровне руководителей СССР и Югославии в 1946-1980 гг: В 2 т. Т. 1: 1946-1964 / гл. ред. М. Милошевич, В. П. Тарасов, Н. Г. Томилина. М.: МФД 2014. 880 с. (Россия. XX век. Документы). С. 599-624.

13. Прибытие в Москву югославской правительственной торговой делегации // Правда. 1954. 19 декабря.

14. Резолюция Информационного бюро о положении в Коммунистической партии Югославии // Правда. 1948. 29 июня.

15. Российский государственный архив социально-политической истории (далее - РГАСПИ). Ф. 17. Центральный Комитет КПСС. ОП. 128. Д. 493.

16. РГАСПИ. Ф.17. Центральный Комитет КПСС. ОП. 128. Д. 668.

17. РГАСПИ. Ф. 82. Молотов Вячеслав Михайлович (1890-1986 гг.). Оп. 2. Д. 1374

18. РГАСПИ. Ф. 82. Молотов Вячеслав Михайлович (1890-1986 гг.). Оп. 2. Д. 1377

19. РГАСПИ. Ф.575. Информационное бюро коммунистических и рабочих партий (1947 - 1956 гг.). Оп. 1. Д. 420.

20. Российский государственный архив экономики (далее - РГАЭ). Ф. 413. Министерство внешней торговли СССР (Минвнешторг СССР). Оп. 37. Д. 11

21. Стыкалин А. С. Проблемы советско-югославских отношений в материалах президиума ЦК КПСС (1953-1964 гг.) // Imagines mundi: альманах исследований всеобщей истории XVI-XX вв. 2010. Сер. Балканика, № 2. С. 179-217.

22. Mates L. Međunarodni odnosi socijalističke Jugoslavije. Beograd, Nolit, 1976. $330 \mathrm{~s}$.

23. Savezni zavod za statističku. Statističku godišnjak SFRJ. Belgrade, 1955. $472 \mathrm{~s}$.

24. Savezni zavod za statističku. Statističku godišnjak SFRJ. Belgrade, 1956. $560 \mathrm{~s}$.

\section{References}

1. Vneshnyaya torgovlya SSSR. Statisticheskii sbornik. 1918-1966. (Foreign Trade of the USSR. Statistical Abstract) Moscow: Mezhdunarodnye otnosheniya, 1967. 245 p. (In Russian).

2. Edemskii A. B. Yugoslaviya $\vee 50-e$ gody: $v$ poiskakh "autentichnogo» marksizma» (Yugoslavia in the 50s: in Search of "Authentic» Marxism») // Yugoslaviya v XX veke: Ocherki politicheskoi istorii / ed. by K. V. Nikiforov. Moscow: Indrik, 2011. P. 595-616. (In Russian).

3. Kostin A. A. «Proshchai, dyadya Dzho! Zdravstvui, dyadya Sem!»: rol' SShA v razvitii otnoshenii Yugoslavii s Zapadom $\checkmark$ 1949-1953 gg. («Goodbye, Uncle Joe! Hello, Uncle Sam!» The Role of the United States in the Development of Relations between Yugoslavia and the West in 1949-1953) // Vestnik Vyatskogo gosudarstvennogo universiteta. 2011. No. 4-1. Istoriya. Istoricheskie nauki. P. 57-68. (In Russian).

4. Kostin A. A. Ekonomicheskie otnosheniya Yugoslavii i Soedinennykh Shtatov 1945-1948 gg. (Economic Relations of Yugoslavia and the United States 1945-1948) // Yaroslavskii pedagogicheskii vestnik. 2011. No. 3. Vol. I (Gumanitarnye nauki). P. 96-101. (In Russian).

5. Lakovich I. Pereorientatsiya yugoslavskoi voennoi politiki (1956-1961 gg.). (Reorientation of Yugoslav Military Policy (1956-1961) // Slavyanskii mir $\vee$ tret'em tysyacheletii. Soglashenie (soglasie), dogovor, kompromiss $\vee$ istorii, yazykakh i kulture slavyanskikh narodov. Moscow: Institute of slavic studies of RAS, 2016. P. 209-224. (In Russian).

6. Maksakova M. A. Tendentsii razvitiya ekonomicheskogo sotrudnichestva Rossii i stran Zapadnykh Balkan. (Trends in the Development of Economic Cooperation between Russia and the Western Balkans): abstract of thesis. Moscow, 2015. $20 \mathrm{~s}$. (In Russian).

7. Milovanov V. S. Sovetsko-yugoslavskie ekonomicheskie otnosheniya. (Soviet-Yugos/av Economic Relations). Moscow Nauka, 1978. 152 p. (In Russian).

8. Postanovlenie Prezidiuma TsK KPSS «O vozobnovlenii ekonomicheskikh i kul'turnykh svyazei mezhdu SSSR i Yugoslaviei». (Decree of the Presidium of the Central Committee of the CPSU «On the Renewal of Economic and Cultural Ties between the USSR and Yugos/avia") // Vstrechi i peregovory na vysshem urovne rukovoditelei SSSR i Yugoslavii v 1946-1980 gg: In 2 Vols. Vols. 1: 1946-1964 / ed. by M. Miloshevich, V. P. Tarasov, N. G. Tomilina. Moscow: MFD, 2014. (Rossiya. XX vek. Dokumenty). P. 575-578. (In Russian).

9. Postanovlenie Prezidiuma TsK KPSS «O meropriyatiyakh po razvitiyu sovetsko-yugoslavskikh otnoshenii). (Decree of the Presidium of the Central Committee of the CPSU "On Measures to Develop Soviet-Yugoslav Relations») (/ Vstrechi i peregovory na vysshem urovne rukovoditelei SSSR i Yugoslavii v 1946-1980 gg: In 2 Vols. Vols. 1: 1946-1964 / ed. by M. Miloshevich, V. P. Tarasov, N. G. Tomilina. Moscow: MFD, 2014. (Rossiya. XX vek. Dokumenty). P. 627. (In Russian).

10. Postanovlenie Prezidiuma TSK KPSS «Ob agremane poslu Yugoslavii v SSSR Vidich Dobrivoe». (Decree of the Presidium of the Central Committee of the CPSU «On the Agrement to the Ambassador of Yugoslavia in the USSR Vidic Dobrivoje") /( Vstrechi i peregovory na vysshem urovne rukovoditelei SSSR i Yugoslavii v 1946-1980 gg: In 2 Vols. Vols. 1 : 1946-1964/ed. by M. Miloshevich, V. P. Tarasov, N. G. Tomilina. Moscow: MFD, 2014. (Rossiya. XX vek. Dokumenty). P. 574575. (In Russian). 
11. Postanovlenie Prezidiuma TsK KPSS «Ob ukazaniyakh sovposlu v Yugoslavii». (Decree of the Presidium of the Central Committee of the CPSU "On Instructions to the Soviet Ambassador in Yugoslavia») // Vstrechi i peregovory na vysshem urovne rukovoditelei SSSR i Yugoslavii v 1946-1980 gg: In 2 Vols. Vols. 1: 1946-1964 / ed. by M. Miloshevich, V.P. Tarasov, N.G. Tomilina. Moscow: MFD, 2014. (Rossiya. XX vek. Dokumenty). P.575. (In Russian).

12. Postanovlenie Prezidiuma TsK KPSS «Proekt rezolyutsii Prezidiuma TsK KPSS po dokladu pravitel'stvennoi delegatsii SSSR o peregovorakh S Yugoslaviei». (Decree of the Presidium of the Central Committee of the CPSU "Draft resolution of the Presidium of the Central Committee of the CPSU on the Report of the Governmental Delegation of the USSR about Negotiations with Yugoslavia") // Vstrechi i peregovory na vysshem urovne rukovoditelei SSSR i Yugoslavii v 1946-1980 gg: In 2 Vols. Vols. 1: 1946-1964/ ed. by M. Miloshevich, V. P. Tarasov, N. G. Tomilina. Moscow: MFD, 2014. (Rossiya. XX vek. Dokumenty). P. 599-624. (In Russian).

13. Pribytie $v$ Moskvu yugoslavskoi pravitel'stvennoi torgovoi delegatsii. (Arrival of the Yugos/av Government Trade Delegation at Moscow) // Pravda. 1954. Desember 19. (In Russian).

14. Rezolyutsiya Informatsionnogo byuro o polozhenii v Kommunisticheskoi partii Yugoslavii. (Resolution of the Information Office on the Situation in the Communist Party of Yugoslavia) // Pravda. 1948. June 29. (In Russian).

15. Russian state archive social and political history (RGASPI). F.17. Tsentral'nyi Komitet KPSS. Inv.128. D.493. (In Russian).

16. RGASPI. F.17. Tsentral'nyi Komitet KPSS. Inv. 128. D. 668. (In Russian)

17. RGASPI. F.82. Molotov Vyacheslav Mikhailovich (1890-1986 gg.). Inv.2. D.1374. (In Russian).

18. RGASPI. F.82. Molotov Vyacheslav Mikhailovich (1890-1986 gg.). Inv.2. D. 1377. (In Russian).

19. RGASPI. F.575. Informatsionnoe byuro kommunisticheskikh i rabochikh partii (1947-1956 gg.). Inv.1. D.420. (In Russian).

20. Rossiiskii gosudarstvennyi arkhiv ekonomiki (dalee-RGAE). F.413. Ministerstvo vneshnei torgovli SSSR (Minvneshtorg SSSR). Inv.37. D.11. (In Russian).

21. Stykalin A. S. Problemy sovetsko-yugoslavskikh otnoshenii v materialakh prezidiuma TsK KPSS (1953-1964 gg.). (Problems of Soviet-Yugoslav relations in the materials of the Presidium of the Central Committee of CPSU (1953-1964) /I Imagines mundi: al'manakh issledovanii vseobshchei istorii XVI - XX vv. Ser. Balkanika. 2010. No.2. P. 179-217. (In Russian).

22. Mates L. Međunarodni odnosi socijalističke Jugoslavije. (Foreign Affairs of Socialist Yugos/avia). Beograd, Nolit, 1976. 330 p. (In Serbian).

23. Savezni zavod za statističku. Statističku godišnjak SFRJ. (Federal Bureau of Statistics. Statistical Yearbook of the SFRY). Belgrade, 1955. 472 p. (In Serbian).

24. Savezni zavod za statističku. Statističku godišnjak SFRJ. (Federal Bureau of Statistics. Statistical Yearbook of the SFRY). Belgrade, 1956. 560 p. (In Serbian). 